\title{
Blast furnaces' mud: waste or a new by-product?
}

\author{
N. Quaranta, M. Caligaris, H. López, M. Unsen \& C. Giansiracusa \\ Grupo de Estudios Ambientales, \\ Facultad Regional San Nicolás Universidad Tecnológica Nacional, \\ San Nicolás, Argentina
}

\begin{abstract}
Industrial residues reuse consists of redirecting the waste materials to new production processes, instead of sending them to the waste flow. Usually, previous treatments are required as a way to transform these wastes into raw materials for the same industry or for others.

In this work waste materials from a steel factory were studied. They consist of the waste mud coming from the blast furnace and from the converter. Most of these materials are accumulated in the open air, waiting for final disposal.

When analyzing the materials it was determined that the mud from the converter could be incorporated again to the steel production process due to its high iron content. For this reason, subsequent studies were carried out on mud from blast furnaces.

Dense samples with the original material, without additives and with different ratios of sand addition, were prepared. These samples did not sinterize in the studied temperature range $\left(800^{\circ} \mathrm{C}-1300^{\circ} \mathrm{C}\right)$. A third group of samples, with the addition of $20 \%, 40 \%$ and $60 \%$ of discarded glass were made. Sintered samples, with different characteristics, were obtained when treating them at $1200^{\circ} \mathrm{C}$.

Starting from calcined mud, that is, without carbon, samples with similar characteristics were also prepared. After heat treatment, dense bodies were obtained, with suitable characteristics.
\end{abstract}

Keywords: recycling, wastes, iron and steel industry, mud. 


\section{Introduction}

Industrial residues reuse consists of redirecting the waste materials to new production processes, instead of sending them to the waste flow. Usually, previous treatments are required in order to transform these wastes into raw materials for the same industry or for others.

Most of the wastes from the iron and steel sectors are characterized by their high metal content. The problem lies in recovery systems cost that does not generally make the result financially worthwhile. That's why the vitrification processes and the production of vitroceramic dense materials appear as options to increase the wastes value and prevent them from being set for disposal $[1,2]$. These materials, powder, slag, mud, etc., are relatively easy to include in useful materials for the construction industry, if adequate compositions are designed to integrate the different oxides. Alumina is one of the most important oxides to take into account, since its presence in the mixtures quite often determines the sinterization and the melting points. As alumina content increases, so does the melting point: this fact is unfavorable in industrial applications [3]. Sometimes it is necessary to add fusing materials to reduce the working temperatures to industrial levels.

In this work waste materials from a steel factory were studied with the aim of characterizing and analyzing the feasibility of their use. They consist of the waste mud coming from the blast furnace and from the converter. Most of these materials are accumulated in the open air, waiting for final disposal. The industrial process that generates the wastes was analyzed in order to determine the possible influence of the different stages of production on the studied wastes characteristics (See Figures 1 and 2) [4].

\section{Experimental}

In order to analyze the possibility of using the wastes as raw materials to obtain useful products, probes with mud particle sizes less than $600 \mu \mathrm{m}$ were prepared. These powders were uniaxially pressed $(100 \mathrm{MPa})$ without the addition of other components.

Other samples, with sand addition $(20 \%, 40 \%$ and $60 \%)$ and discarded glass $(20 \%, 40 \%$ and $60 \%)$, were prepared with the aim of lowering the sintering temperature to obtain dense bodies.

Samples with similar characteristics, but starting from calcined mud, were also prepared eliminating the original $\mathrm{C}$ by thermal treating at $700^{\circ} \mathrm{C}$ for 3 hours.

All the compacts were heat treated in the range $1000^{\circ} \mathrm{C}-1300^{\circ} \mathrm{C}$, in order to determine the sintering temperature of the samples.

The powders to be used as raw material for the dense bodies' production and the fired samples obtained were characterized by several techniques: optical and scanning electron microscopies (SEM), electron diffraction analysis X-ray (EDAX), particle size distribution, and Vickers microhardness measurements. 


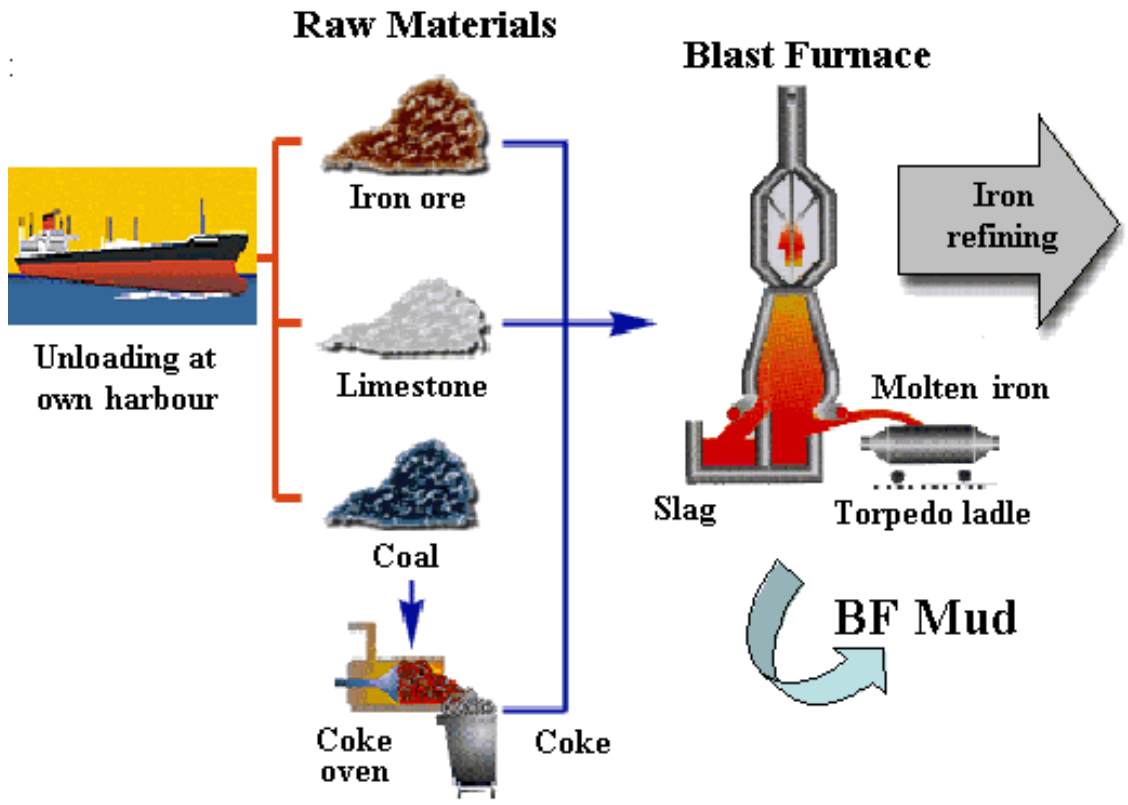

Figure 1: $\quad$ First stage: mineral reduction.
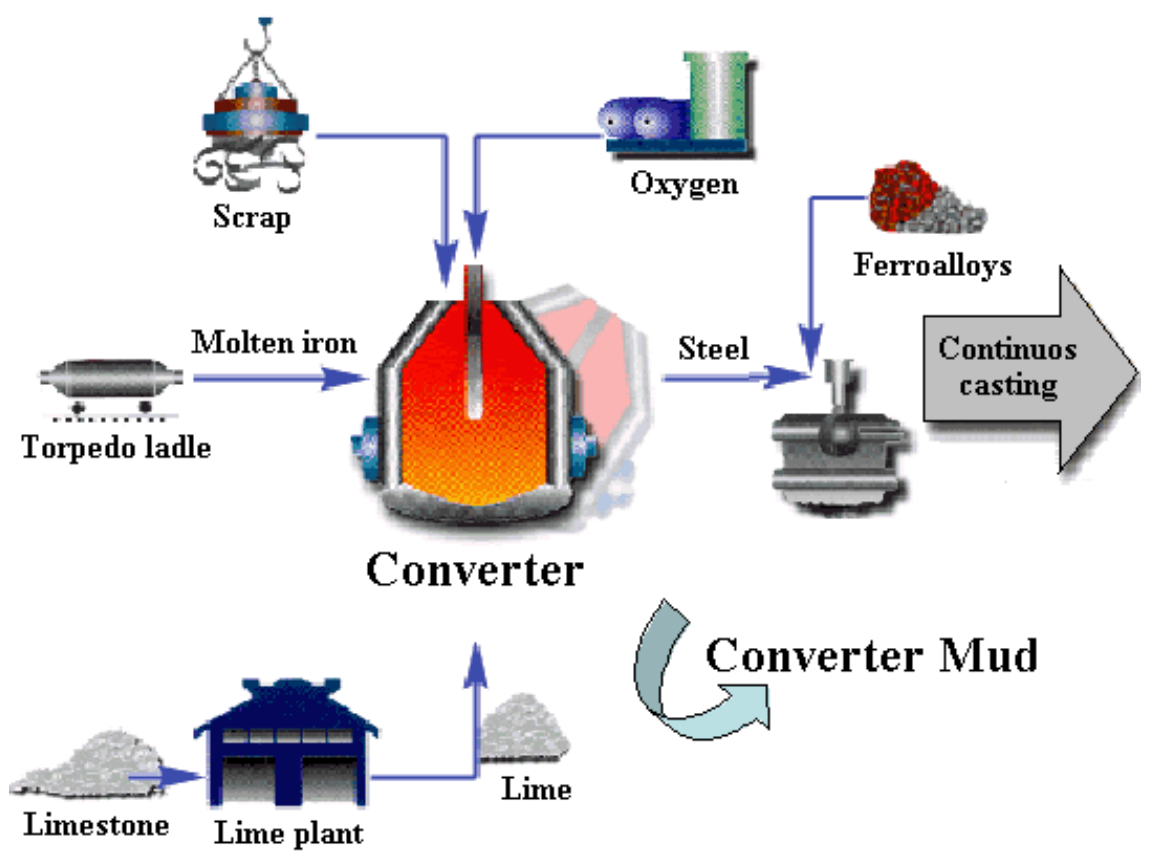

Figure 2: $\quad$ Second stage: steel production. 
The SEM analyses were carried out using a Phillips 515 scanning electronic microscope with an X-ray detector (EDAX-Phoenix).

The optical observations were made with Zeiss-Axiotech equipment with a Donpisha 3CCD camera and image scanner.

The hardness analyses were made with a Vickers indenter in an HMV-2000 Shimatzu equipment, using loads of $100 \mathrm{~g}$ for $10 \mathrm{sec}$ in all cases.

\section{Results and discussion}

Table 1 shows the chemical analysis of the powders: converter and blast furnace (BF) mud.

As it can be observed, the $\mathrm{Fe}_{2} \mathrm{O}_{3}$ content in the converter mud is higher than $80 \%$, and then converter mud can be reused in the steel making process, if it is adequately shaped as briquettes. For this reason, this work essentially focuses on the reusing of $\mathrm{BF}$ mud.

The method used to determine the chemical composition doesn't take into account the samples carbon content. Therefore, calcination weight loss analyses were carried out, obtaining $38 \%$ weight loss.

Table 1: $\quad$ EDS chemical composition [\%].

\begin{tabular}{|c|c|c|c|c|c|c|c|}
\hline Oxide & $\mathrm{Fe}_{2} \mathrm{O}_{3}$ & $\mathrm{SiO}_{2}$ & $\mathrm{CaO}$ & $\mathrm{Al}_{2} \mathrm{O}_{3}$ & $\mathrm{ZnO}$ & $\mathrm{K}_{2} \mathrm{O}$ & $\mathrm{MnO}$ \\
\hline $\begin{array}{c}\text { Converter } \\
\text { Mud }\end{array}$ & 83.61 & 4.85 & 9.60 & --- & --- & --- & 1.94 \\
\hline BF Mud & 47.45 & 33.04 & 1.30 & 14.42 & 2.30 & 0.66 & 0.83 \\
\hline
\end{tabular}

Table 2: $\quad$ BF mud particle size distribution.

\begin{tabular}{|c|c|c|c|}
\hline Mesh & Size & \% Weight & \% Accumulated \\
\hline 30 & $>600 \mu \mathrm{m}$ & 54.9 & 54.9 \\
\hline 50 & $600-300 \mu \mathrm{m}$ & 16.0 & 70.9 \\
\hline 70 & $300-212 \mu \mathrm{m}$ & 4.0 & 74.9 \\
\hline 100 & $212-150 \mu \mathrm{m}$ & 7.9 & 82.8 \\
\hline 200 & $150-75 \mu \mathrm{m}$ & 8.2 & 91.0 \\
\hline Bottom & $<75 \mu \mathrm{m}$ & 9.0 & 100.0 \\
\hline
\end{tabular}

Particle size distribution of $\mathrm{BF}$ mud, heat treated at $100^{\circ} \mathrm{C}$, is shown in Table 2. As it can be observed, an important percentage of the sample has sizes higher than $600 \mu \mathrm{m}$. Actually, those are not dense particles but smaller particles agglomerates that can easily get loose. This fact can be observed by scanning electron microscopy as well as the powders microstructure (Figure 3 ). 
The samples without additives and those with sand addition $(20 \%, 40 \%$ and $60 \%$ ), did not sinterize in the studied temperature range.
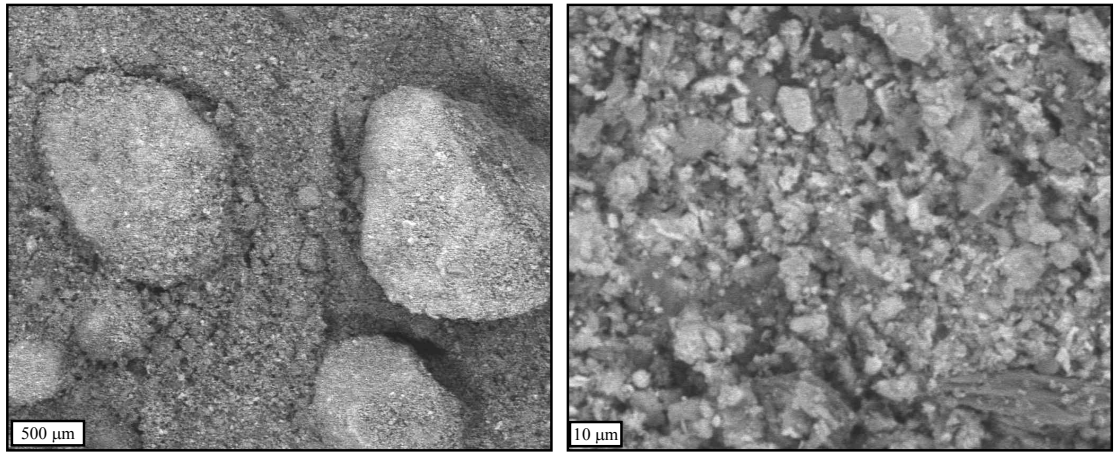

Figure 3: $\quad$ BF mud SEM micrographs.

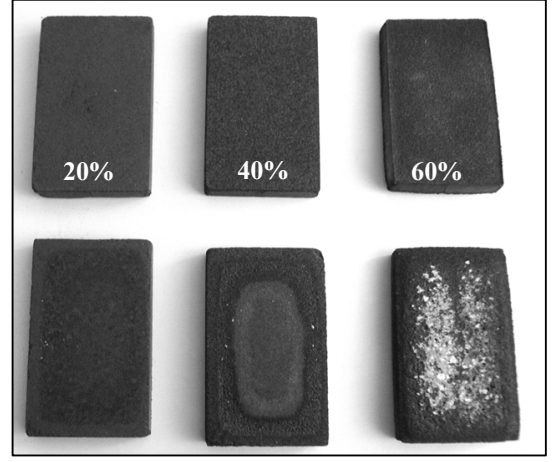

(a)

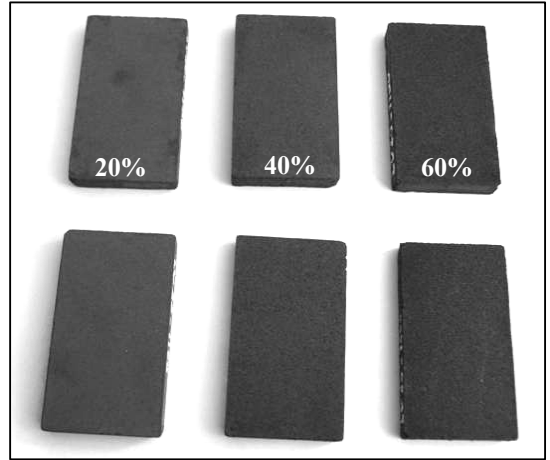

(b)

Figure 4: $\quad$ Dense bodies from BF mud with glass addition. T: $1200^{\circ} \mathrm{C}$ (a) with initial C content; (b) with initial C elimination.

Samples with discarded glass addition (20\%, 40\% and 60\%) sinterized at $1200^{\circ} \mathrm{C}$ (Figure $4 \mathrm{a}$ ). Samples with $20 \%$ glass show low sintering degree, with a loose structure. Dark zones can also be observed due to the carbon segregation towards the support surface. In samples containing $40 \%$ and $60 \%$ as well as de carbon segregation, zones with molten glass, with edges loss, are obtained. In the case of samples with higher glass content, consolidation with the alumina base used as samples support during firing was produced.

Similar samples, starting from BF mud heat treated to eliminate the $\mathrm{C}$ present in the original material were designed. This fact, on the one hand, prevents the carbonous phase segregation and, on the other hand, indirectly increases the alumina proportion in the mixtures, avoiding the dripping of liquid phases developed during the heat treatment. These samples, with $20 \%, 40 \%$ and $60 \%$ glass content had the same sintering temperature: $1200^{\circ} \mathrm{C}$, and are shown in 
Figure 4b. They also showed homogeneous superficial appearance, with well defined edges and high sintering degree.

Porosity analyses show greater porosities with lower glass content, as can be observed in Figure 5. In this figure, photographs obtained by optical microscopy, were also included.

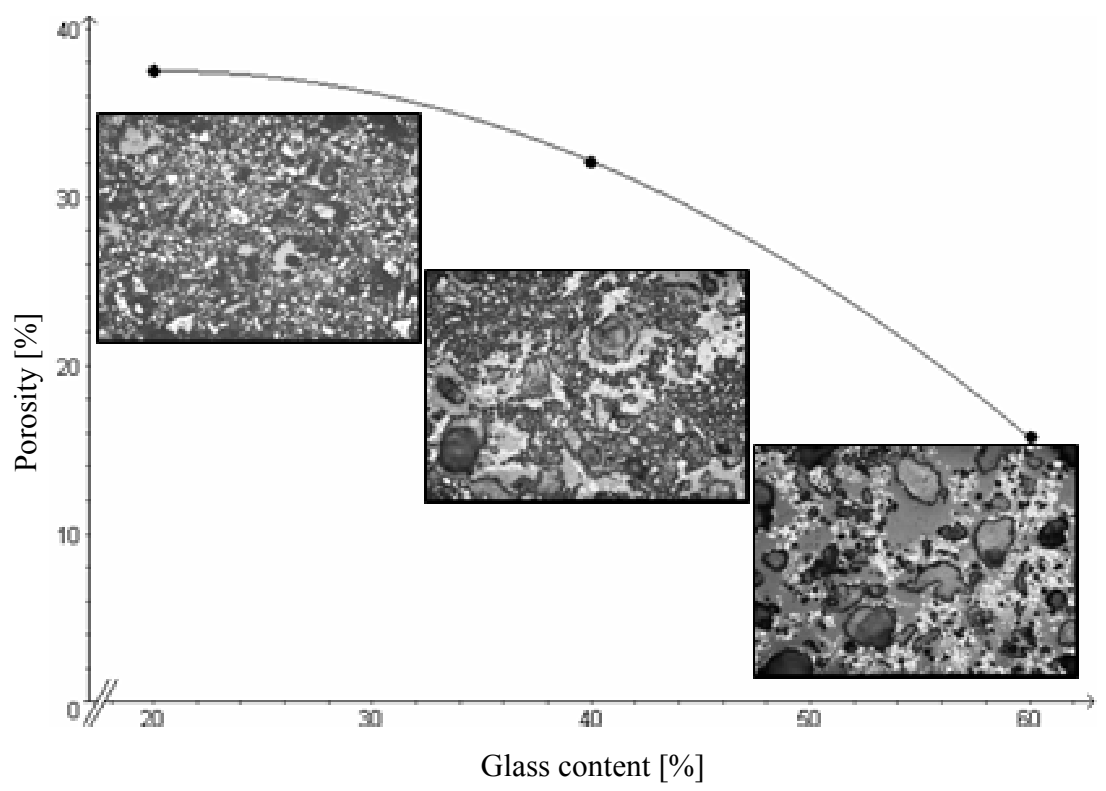

Figure 5: Samples porosity vs. glass content. Temperature: $1200^{\circ} \mathrm{C}$. Magnification 100X.

Samples with $20 \%$ glass have the highest porosity, with little vitreous phase. Although the structure is sinterized, the shape and size of the particles initially mixed can be clearly appreciated. Samples with $40 \%$ glass have lower porosity, with the presence of vitreous zones due to liquid formation during the sintering process. The samples with $60 \%$ glass treated at $1200^{\circ} \mathrm{C}$, show low porosity due to an important liquid phase formation during heating that is observed in optical micrographs as a vitreous dense matrix, with little presence of pores.

The permanent linear expansion essays of the samples resulted with values between $-1,2 \%$ and $1,5 \%$ in samples length, in those prepared with the original $\mathrm{C}$ content, whereas in compacts obtained with calcined mud, these values varied between $0,3 \%$ and $1 \%$. That is, the last ones present higher dimensional stability.

The observed microstructural characteristics in bodies with high content of glass, together with the high density values generally lead to more fragile and less heat insulating materials.

With the aim of improving the general properties of the materials and decreasing the sintering temperature, samples with $60 \%$ glass heat treated at $1100^{\circ} \mathrm{C}$ were prepared. 
In this way, materials with better properties were obtained: porosities of $25 \%$ approximately and more homogeneous distribution of the vitreous matrix. The most important characteristic is the superficial appearance of the samples that, even though they have no macroscopical differences, at microscopical scale it can be observed that probes treated at $1200^{\circ} \mathrm{C}$ suffered a noticeable superficial bubbling while samples treated at $1100^{\circ} \mathrm{C}$ maintained their edges and showed no signs of bubbling. This fact can be seen in Figure 6 .

The superficial microhardness analysis of the samples was made using low load and time, $100 \mathrm{~g}$ for 10 seconds, because with higher loads it was not possible to obtain clear stamps feasible to measure due to the very low tenacity of these sectors.

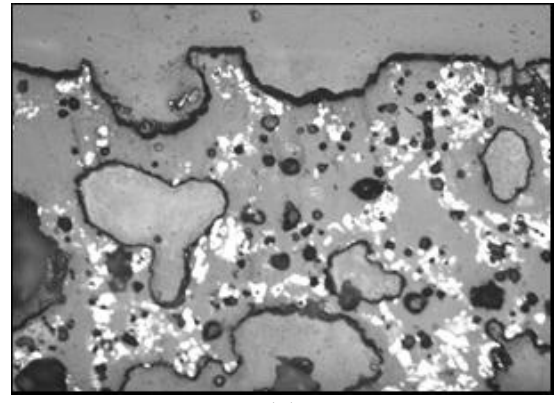

(a)

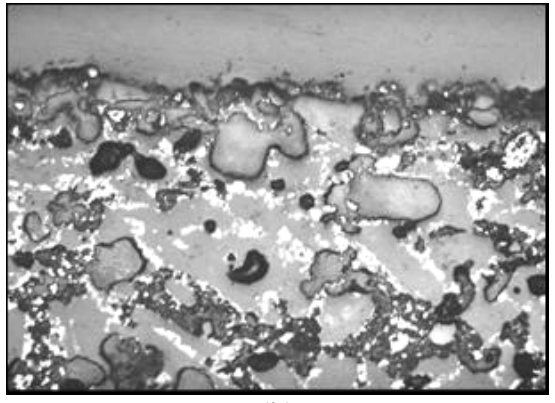

(b)

Figure 6: Microscopical superficial appearance of $60 \%$ glass samples. Magnification $100 \mathrm{X}$. (a) $1200^{\circ} \mathrm{C}$; (b) $1100^{\circ} \mathrm{C}$.

Table 3: $\quad$ Vickers microhardness of the samples.

\begin{tabular}{|c|c|c|c|c|}
\hline Sample & $\begin{array}{c}20 \% \\
1200^{\circ} \mathrm{C}\end{array}$ & $\begin{array}{c}40 \% \\
1200^{\circ} \mathrm{C}\end{array}$ & $\begin{array}{c}60 \% \\
1200^{\circ} \mathrm{C}\end{array}$ & $\begin{array}{c}60 \% \\
1100^{\circ} \mathrm{C}\end{array}$ \\
\hline $\begin{array}{c}\mathrm{Hv}\left[\mathrm{Kg} / \mathrm{mm}^{2}\right] \\
\text { Zone S }\end{array}$ & 620 & 546 & 458 & 566 \\
\hline $\begin{array}{c}\mathrm{Hv}\left[\mathrm{Kg} / \mathrm{mm}^{2}\right] \\
\text { Zone V }\end{array}$ & --- & 630 & 592 & 689 \\
\hline
\end{tabular}

The Vickers microhardness values obtained when using these conditions were determined in different zones of the samples, identified as structural (S) and vitreous (V). In the samples with $20 \%$ glass, analysis was made only in the structural zone, due to the scarce presence of vitreous phase and their little size. The Vickers microhardness measurements are shown in Table 3.

The microhardness values obtained as the average of 10 measurements showed $10 \%$ dispersion. The values obtained for the dense vitreous phase (zone $\mathrm{V}$ in Table 3) result higher than those found in the literature for commercial glass $\left(571 \mathrm{Kg} / \mathrm{mm}^{2}\right)$, alkali glass $\left(565 \mathrm{Kg} / \mathrm{mm}^{2}\right)$ and silicoaluminous glass $(620.4$ $\mathrm{Kg} / \mathrm{mm}^{2}$ ) [5]. This fact can be explained due to the presence of reinforcement 
phases, with rod shapes, observed by microscopical analysis as integrated to the vitreous matrix (Figure 7).

The X-Ray patterns of the mud (calcined and non-calcined) reveal the same diffractions peaks, assigned to hematite- $\mathrm{Fe}_{2} \mathrm{O}_{3}$, (pdf. 871166), and quartz- $\mathrm{SiO}_{2}$ (pdf. 851054), whereas the patterns of the fired samples show the disappearance of the quartz peaks and the appearance of a new phase whose main peak appears at $2 \Theta=29.97$ and has been identified as a compound silicate of aluminum, calcium and magnesium (pdf. 781391).

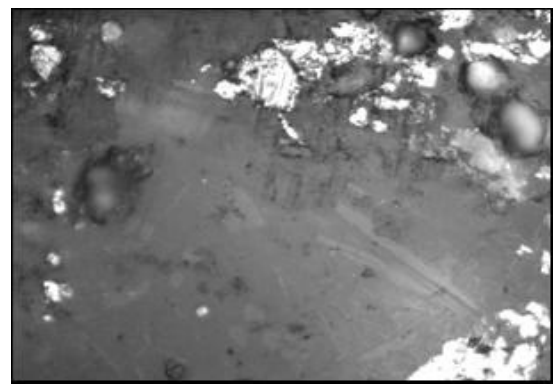

(a)

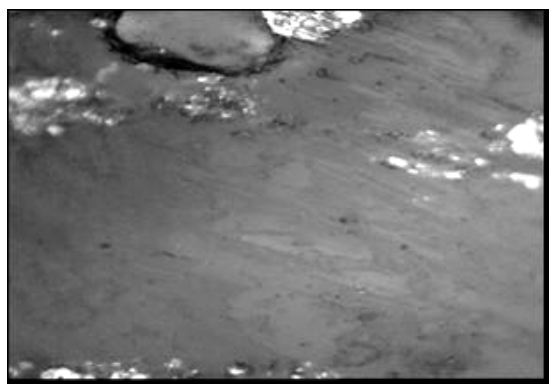

(b)

Figure 7: Reinforcement phases on vitreous matrix in $60 \%$ glass probes. Magnification 500X. (a) $1200^{\circ} \mathrm{C}$; (b) $1100^{\circ} \mathrm{C}$.

It can be inferred from the results of those studies that these mud, wastes from the steel production process, can be reused for the production of sintered bodies, resulting the best conditions among those analyzed, the mixture of calcined original material with $40 \%$ discarded glass heat treated at $1200{ }^{\circ} \mathrm{C}$ and with $60 \%$ discarded glass heat treated at $1100^{\circ} \mathrm{C}$. The choice of the production conditions will be subordinated to economical decisions and the availability of the involved raw materials.

\section{Conclusions}

With the temperatures usually used in the ceramic industry, the samples obtained from BF mud, without other components addition, did not achieve sinterization. With glass addition, dense bodies were obtained, with good mechanical resistance, but with the presence of fragile zones, with different microstructure due to phase segregation. The compacts obtained from the calcined original material (C elimination) showed the best mechanical - structural characteristics.

From the results of those studies it can be concluded that the wastes from steel production process analyzed in the present work, can be reused for the production of sintered bodies, resulting the best conditions among those analyzed, the mixture of calcined original material with $40 \%$ discarded glass heat treated at $1200^{\circ} \mathrm{C}$ and with $60 \%$ discarded glass heat treated at $1100^{\circ} \mathrm{C}$. 


\section{Acknowledgements}

The authors wish to thank Siderar SAIC for the wastes used in the present work. Support by CICPBA is gratefully acknowledged.

\section{References}

[1] A. Karamanov et al., "Iron-rich sintered glass-ceramics from industrial wastes", Journal of the American Ceramic Society, Vol. 82 [11] (1999) p.3012-3016.

[2] M. Romero et al., "Preparation and properties of high iron oxide content glasses obtained from industrial wastes", Journal of the European Ceramic Society, Vol. 18 (1998) p.153-160.

[3] X. E. Castells, "Reciclaje de Residuos Industriales", Ed. Díaz de Santos, Madrid, España. (2000) p. 306.

[4] http://www.infoacero.cl/procesos/siderur.htm

[5] I. J. McColm, "Ceramic Hardness", Ed. Plenum Press, New York, (1990) p. 242-243. 